EESTI NSV TEADUSTE AKADEEMIA TOIMETISED. 25. KOIDE

FOUSIKA * MATEMAATIKA. 1976, NR. 1

ИЗВЕСТИЯ АКАДЕМИИ НАУК ЭСТОНСКОИ ССР. ТОМ 25 ФИЗИКА * МАТЕМАТИКА, 1976, Nㅛ 1

\title{
ГРАВИТАЦИОННОЕ ТЕЧЕНИЕ НЕНЬЮТОНОВСКИХ ЖИДКОСТЕЙ ПРИ СЕПАРАЦИИ МАТЕРИАЛА В ПЛЕНКУ
}

Во многих энергетических и энерготехнологических установках высокотемпературное стекание жидкостей по поверхностям сопровождается непрерывной сепарацией материала из газовой среды в пленку $\left[{ }^{1-5}\right]$. Стекание происходит в условиях интенсивного теплообмена, что является основной причиной неньютоновского поведения материала в этих установках, так как температура, а вместе с ней и жидкостные свойства материалов изменяются по толщине пленки в широких пределах. В каждой установке стекающая пленка играет определенную роль. В энергетических установках она обеспечивает выход высепарированного материала и защиту поверхностей от высокотемпературной среды $\left[{ }^{1-4}\right]$; в энерготехнологических, кроме того, способствует обработке технологического сырья в пленке $\left[{ }^{2}\right]$; в химико-технологических агрегатах наряду с выводом высепарированного материала содействует протеканию соответствующих процессов $\left[{ }^{6,7}\right]$; в магнитогидродинамических генераторах предохраняет стенки от перегрева, причем пленка здесь не должна заметно ухудшать электрические показатели установки $\left[{ }^{5,8}\right]$.

Стекание материалов по поверхностям во многом зависит от их свойств. Поэтому знание физико-химических особенностей материалов является определяющим моментом при установлении оптимальных режимов работы установок.

Для более распространенных неньютоновских жидкостей напряжение сдвига выражается следующими уравнениями $\left[{ }^{9}\right]$ :

$$
\begin{aligned}
& \tau=k\left(d w_{x} / d y\right)^{n} \\
& \tau=\tau_{0}+\eta d w_{x} / d y \\
& \tau=\tau_{0}+k\left(d w_{x} / d y\right)^{n} \\
& \text { (модель Оствальда де Виля), } \\
& \text { (модель Шведова-Бингама), } \\
& \text { (модель Бингама). }
\end{aligned}
$$

Многие энергетические шлаки и энерготехнологическое сырье в широком диапазоне температур перед полным плавлением находятся в пластическом состоянии, т. е. являются неньютоновскими жидкостями $\left[{ }^{10-12}\right]$.

Константы $k, n, \tau_{0}$ и $\eta$ в формулах (1)-(3) сильно зависят от температуры. На основе опытных данных, температурная зависимость $k$ и $n$ различных энергетических сланцевых шлаков $\left[{ }^{12}\right]$ описывается формулами 
и $\quad \begin{aligned} k & =K_{1} \Delta T^{-m_{1}} \\ n & =K_{2} \Delta T^{-m_{2}} .\end{aligned}$

$$
n=K_{2} \Delta T^{-m_{2}} \text {. }
$$

Для изученных пластических сланцевых шлаков $\tau_{0}=0$. Однако для пластических шлаков канско-ачинских углей $\tau_{0}>0\left[{ }^{10}\right]$, причем $\tau_{0}$ увеличивается с уменьшением температуры по эмпирической формуле

$$
\tau_{0}=K_{3} \Delta T^{-m_{3}} \text {. }
$$

Ньютоновская вязкость большинства энергетических шлаков выражается в виде $\left[{ }^{3}\right]$;

$$
\eta=K_{4} \Delta T^{-m_{4}}
$$

Допустим, что изменение температуры по всему стекающему слою жидкости с толщиной $\delta_{x}$ линейно из-за относительной тонкости последнего. Тогда зависимости (4)-(7) можно записать следующим обра3ом:

$$
\begin{aligned}
k & =K^{\prime}{ }_{1}\left(\delta_{x} / y\right)^{m^{\prime}}, \\
n & =K^{\prime}{ }_{2}\left(\delta_{x} / y\right)^{m_{2}}, \\
\tau_{0} & =K^{\prime}{ }_{3}\left(\delta_{x} / y\right)^{m^{\prime}}, \\
\eta & =K^{\prime}{ }_{4}\left(\delta_{x} / y\right)^{m^{\prime}},
\end{aligned}
$$

Уравнение ламинарного гравитационного стекания жидкостей по вертикальным и наклонным поверхностям имеет вид

$$
d \tau / d y+g \varrho \xi=0 .
$$

Если в уравнении (12) $\tau$ выразить формулами (1)-(3) и подставить в них соответствующие выражения $k, n, \tau_{0}$ и $\eta$ из равенств (8)-(11), то получим

$$
\begin{gathered}
d / d y\left[K^{\prime}{ }_{3}\left(\delta_{x} / y\right)^{m_{3}}+K^{\prime}{ }_{4}\left(\delta_{x} / y\right)^{m_{4}^{\prime}} d w_{x} / d y\right]=-g Q \xi \\
d / d y\left[K^{\prime}{ }_{3}\left(\delta_{x} / y\right)^{m_{3}^{\prime}}+K_{1}^{\prime}{ }_{1}\left(\delta_{x} / y\right)^{m_{1}^{\prime}}\left(d w_{x} / d y\right)^{K_{2}^{\prime}\left(\delta_{x} / y\right)^{m_{2}}}\right]=-g Q \xi .
\end{gathered}
$$

Уравнение (13) действительно для неньютоновских жидкостей типа Шведова-Бингама, а уравнение (14) - для жидкостей, напряжение сдвига которых выражается моделями Оствальда де Виля $\left(K_{3}^{\prime}=0\right.$ и $m_{3}^{\prime}=0$ ) или Бингама.

Для решения уравнений (13) и (14) выбраны следующие граничные условия:

$$
\begin{array}{rlll}
\left(d w_{x} / d y\right)_{y=\delta_{x}}=0 & \text { при } & y=\delta_{x} \\
w_{x}=0 & \text { при } & y=0 .
\end{array}
$$

Уравнение неразрывности стекания жидкостей при равномерной сепарации их на поверхностях определяется из формулы

$$
\delta_{x} \bar{w}_{x}=G_{\text {шл }} x / \mathrm{Q} .
$$

Уравнения (13) и (14) с учетом граничных условий и уравнения неразрывности (15) были решены численно на ЭВМ «Наири» методом Рунге-Кутта, причем $\bar{w}_{x}$ была найдена по формуле Симпсона. Для примера проведены расчеты стекания пластического шлака ленинградского сланца. Начальные данные шлака (определены экспериментально): дилатантная жидкость $(n>1)$ описывается моделью Оствальда де Виля - уравнением (1); $T_{1}=T_{0}=1603 \mathrm{~K} ; T^{\prime}=1466 \mathrm{~K} ; \eta_{0}=$ $=0,6 \mathrm{Hc} / \mathrm{M}^{2} ; \quad \varrho=3000 \kappa 2 / \mathrm{m}^{3} ; \quad K_{1}{ }^{\prime}=0,243 ; \quad K_{2}{ }^{\prime}=1,16 ; \quad K_{3}{ }^{\prime}=0 ;$ $m_{1}^{\prime}=1 ; m_{2}^{\prime}=1 / 2 ; m_{3}^{\prime}=0$.

Результаты расчетов приведены в таблице и показаны на рисунке. Видно, что стекание полностью пластического шлака $\left(T_{1}=T_{0}\right)$ по вер- 
тикальным и сильно наклонным $\left(\alpha=5^{\circ}\right)$ поверхностям с различными степенями высепарирования шлака в пленку происходит нормально. Это объясняется в первую очередь тем, что шлаки ленинградского сланца, как и эстонского, превращаются в истинные жидкости при очень малых вязкостях $\left(\eta_{0}=0,1-0,8 \mathrm{Hc} / \mathrm{s}^{2}\right)$. Поэтому нельзя не учитывать стекания шлаков этих топлив в пластической области. Расчеты показывают, что по численным решениям уравнений (13) и (14) можно точнее судить о процессах тепло- и массообмена в различных энергетических и технологических установках, а также в магнитогидродинамических генераторах.

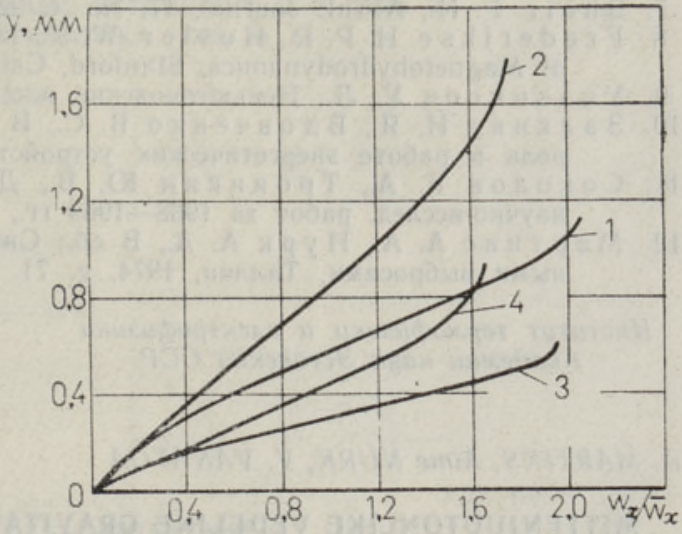

Профили относительных скоростей шлака ленинградского сланца (номера вариантов см. в таблице).

Таб̆лица

\begin{tabular}{|c|c|c|c|c|}
\hline \multirow{2}{*}{ Величина } & \multicolumn{4}{|c|}{ Варианты } \\
\hline & 1 & 2 & 3 & 4 \\
\hline $\begin{array}{l}G_{\mathrm{m} \pi}, \kappa 2 / M^{2} c \\
\delta_{x=1,}, M M \\
\bar{w}_{x=1}, M, M\end{array}$ & $\begin{array}{l}1,0 \\
1,127 \\
0,887\end{array}$ & $\begin{array}{l}0,087 \\
1,796 \\
0,557\end{array}$ & $\begin{array}{l}1,0 \\
0,592 \\
0,338\end{array}$ & $\begin{array}{r}0,087 \\
0,928 \\
0,215\end{array}$ \\
\hline
\end{tabular}

\section{Обозначения:}
$w_{x}, \bar{w}_{x}-$ соответственно скорость и сред- няя скорость жидкости в сече- нии $x$,
$\delta_{x}$ - толщина слоя жидкости в се- чении $x$,
$\eta, \eta_{c}-$ соответственно вязкость и вяз кость при температуре $T_{0}$,
$\xi$ - синус угла наклона поверхно- сти установки к горизонтали,
Q- плотность жидкости,
$\tau$ - напряжение сдвига,
$\tau_{0}$ - предел текучести.

\section{Л ИТЕ Р А Т У Р A}

1. М а ша к Ю. Л., Топочные устройства с вертикальными циклонными предтопками, М.-Л., 1966 , с. 232.

2. С еме н енко Н. А., Вторичные энергоресурсы промышленности и энерготехнологическое комбинирование, М., 1968, с. 269.

3. Д олежал Р., Топки с жидким шлакоудалением, М., 1959. с. 298.

4. С идельков ский Л. Н., Разработка и исследование циклонных энерготехнологических процессов, Ӓвтореф. докт. дис., М., 1971, с. 12.

5. Bienstock D., Bergman P. D., Henry J. M., Demski R. I., Deme ter J. J., Plants K. P.. 13th National Symp. on the Eng. Aspects of Magnetohydrodynamics, Stanford, Calif., March, 1973, p. 10.

6. Семенов П. А., Рейб ах М. С., Горшков А. С., Хим. пром-сть, № 3,53 (1966). 
7. Shair F. H., AIChE Journal, 17, No. 4, 920 (1971).

8. Frederikse H. P. R., Hosler W. R., 13th National Symp. on the Eng. Aspects of Magnetohydrodynamics, Stanford, Calif., March., 1973, p. 4.

9. У илкинсон У. Л., Неньютоновские жндкости, М., 1964, с. 19.

10. Залкинд И. Я., В довченко В. С., В сб.: Минеральная часть топлива и ее роль в работе энергетических устройств, Алма-Ата, 1971 , с. 97.

11. Соколов Б. А., Т роянкин Ю. В., Докл. научно-техн. конфер. по итогам научно-исслед. работ за 1968-1969 гт., МЭИ, М., 1969, с. 38.

12. М артинс А. А., Нурк А. А., В сб.: Сжигание топлив с минимальными вредными выбросами, Таллин, 1974, с. 71 .

Ннститут термофизики и электрофизики Академии наук Эстонской ССР

Поступила в редакцию $12 / \mathrm{V} 1975$

A. MARTINS, Aime NURK, V. VANATOA

\section{MITTENJUUTONLIKE VEDELIKE GRAVITATSIOONILINE VOOLAMINE KOOS MATERJALI SEPARATSIOONIGA KIHTI}

Artiklis vaadeldakse temperatuurist sõltuvate mittenjuutonlike vedelike (eriti plastiliste energeetiliste šlakkide) voolamist püst- ja kaldpindadel. Esitatakse empiirilised valemid mõningate mittenjuutonlike vedelike kõigi iseloomulike näitajate temperatuurisõltuvuse kohta. Gravitatsiopnilise voolamise vôrrandid on lahendatud numbriliselt raalil «Nairi» Runge-Kutta meetodil.

\section{A. MARTINS, Aime NURK, V. VANATOA}

\section{GRAVITATIONAL FLOW OF NON-NEWTONIAN FLUIDS WITH MATERIAL SEPARATION INTO THE FILM}

In the paper the flow phenomena of temperature-dependent non-Newtonian fluids (particularly the plastic energetic slags) on vertical and inclined surfaces are examined. The empirical formulas for typical temperature-dependent indicators of some nonNewtonian fluids are given. The formulas of non-Newtonian gravitational flow are solved in figures on computer "Nairi" by the Runge-Kutta method. 